\section{Lateralizing value of peri-ictal headache: A study of 100 patients with partial epilepsy}

Article abstract-To determine the lateralizing value of peri-ictal headache, the authors conducted a standardized interview of 100 patients with partial epilepsy, 60 with temporal lobe epilepsy (TLE) and 40 with extratemporal epilepsy (ETE). Peri-ictal headache occurred in 47 of 100 (47\%) patients. Peri-ictal headache was more likely to be ipsilateral to the seizure onset in TLE $(27$ of $30=90 \%$ ) than in ETE (two of $17=12 \% ; p<0.001$ ). For both groups, peri-ictal headache usually conformed to the diagnostic criteria for common migraine ( 18 of $30=60 \%$ in TLE; 7 of $17=41 \%$ in ETE).

NEUROLOGY 2001;56:130-132

\begin{abstract}
A. Bernasconi, MD; F. Andermann, MD, FRCP(C); N. Bernasconi, MD; D.C. Reutens, MD, FRACP; and F. Dubeau, MD FRCP(C)
\end{abstract}

Postictal headache is a common feature of generalized tonic-clonic seizures. In a study of 100 epileptic patients, ${ }^{1}$ postictal headache was found in approximately $50 \%$ of patients, and seizures provoked a syndrome similar to migraine in $50 \%$ of them. Unilateral cephalic pain of epileptic origin was reported in few patients and was found to be associated with temporal or occipital EEG epileptic discharges. However, the pain did not colocalize with the EEG abnormalities. ${ }^{2}$ Exceptionally, headache represents the only ictal symptom. Studies with intracerebral depth electrode recordings $\mathrm{s}^{3,4}$ showed that such headache is ipsilateral to an epileptic discharge arising from the amygdala and the hippocampus.

Despite the evidence for occurrence of peri-ictal headache, there have been only few and contradictory data about its lateralizing value in partial epilepsy. The purpose of this study was to determine the lateralizing value of peri-ictal headache as a clinical symptom in patients with pharmacologically intractable partial epilepsy.

Methods. A standardized interview was used to determine the prevalence, lateralization, and characteristics of headaches in 100 consecutive patients ( 45 men; mean age, 33 years) undergoing presurgical evaluation for refractory partial epilepsy.

Type and seizure focus lateralization was determined by a comprehensive evaluation including video-EEG telemetry and high-resolution MRI, and by response to surgical treatment (68\%). Twenty-six patients $(26 \%)$ underwent invasive recording from stereotactic multiple intracranial depth electrodes, because extracranial EEG recordings did not provide clear lateralization of the seizure onset. Of the 60 patients with temporal lobe epilepsy (TLE), 52 had unilateral epileptic discharges (left TLE, $\mathrm{n}=27$; right TLE, $\mathrm{n}=25$ ), and eight had seizures originating in both tempo-

From the Departments of Neurology and Neurosurgery, McGill University, and Montreal Neurological Institute and Hospital, Quebec, Canada.

Supported by the Savoy Foundation for Epilepsy Research, St. Jean-surRichelieu, Quebec, Canada (A.B.).

Received April 7, 2000. Accepted in final form August 29, 2000.

Address correspondence and reprint requests to Dr. Frederick Andermann, Montreal Neurological Institute and Hospital, 3801 University Street, Montreal H3A 2B4, Quebec, Canada. ral lobes. Seizures in the 40 patients with extratemporal epilepsy (ETE) emanated from the frontal lobe $(\mathrm{n}=13)$, centroparietal region $(\mathrm{n}=19)$, and the occipital lobe $(\mathrm{n}=$ 8). Two patients had bifrontal epileptic foci.

The standardized interview was administered during the patients' stay in the telemetry unit by one of the authors (A.B.), a neurologist (table 1). The interview began with a verbatim record of the description of the headache by the patient. Interictal headache was defined as not temporally related to the seizures. Peri-ictal headache was defined as headache temporally related to the attacks. Peri-ictal headache included preictal and postictal headache. For each headache type, subsequent questions inquired about headache localization, premonitory neurologic symptoms and signs, and general symptoms, as well as headache quality. Migrainous character of the headache was determined according to the diagnostic criteria of the International Headache Society (IHS). ${ }^{5}$ Family history of recurrent headache or migraine was documented according to the criteria when possible.

We analyzed differences between patients with TLE and ETE by use of Fisher's exact test for categorical data and paired Student $t$-test for numerical data. Significance was assumed when $p<0.05$.

Results. Overall, 59 patients $(59 \%)$ reported recurrent headaches. It occurred in 37 of $60(62 \%)$ patients with TLE and in 22 of $40(55 \%)$ patients with $\operatorname{ETE}(p=0.53)$.

Peri-ictal headache. Results are summarized in table 2. Peri-ictal headache was reported by 47 of $100(47 \%)$ patients. Eleven had preictal headache, and 44 patients had postictal headache. Eight patients had both preictal and postictal headache.

Peri-ictal headache was reported by 30 of 60 (50\%) of patients with TLE and by 17 of $40(43 \%)$ patients with ETE. There was no difference in the proportion of patients with peri-ictal headache between the two groups ( $p=0.54)$.

The most severe pain was located in the anterior part of the head in most individuals with peri-ictal headache (29 of $47=62 \%$ ). This was true for patients with TLE $(19$ of $30=63 \%)$ as well as those with ETE (11 of $17=$ $65 \% ; p=1.0)$.

In patients with TLE, peri-ictal headache was ipsilateral to the focus in 27 patients, bilateral in two, and contralateral to the focus in one. In patients with ETE, periictal headache was ipsilateral to the focus in two patients, bilateral in 12 , and contralateral to the focus in three. We 
Table 1 Interview for peri-ictal and interictal headaches in patients with refractory partial epilepsy

I. Do you have headache (HA)?

II. How many types of HA do you think you have?

For each type of HA described in question 2:

1. Do the HA occur together with your seizures?

2. If together, when do the HA occur in respect to the seizure?

3. On which side of the head does the HA begin?

4. On which part of your head do you feel the most severe HA?

5. How is the pain?

6. Is the HA severe enough for you to stop your activity or go to bed?

7. Is the HA made worse by physical activity?

8. How long do the HA last (untreated or unsuccessfully treated)?

9. Do you usually treat HA with drugs?

10. Do drugs relieve the pain?

11. Is the HA associated with nausea and/or vomiting?

12. Is the HA associated with photophobia and/or phonophobia?
$\mathrm{Y} / \mathrm{N}$

$1,2,3$, more

$\mathrm{Y} / \mathrm{N}$

$24 \mathrm{~h}-30 \mathrm{~min}$ before; $30 \mathrm{~min}-0 \mathrm{~min}$ before; after

$\mathrm{R} ; \mathrm{L} ; \mathrm{R}$ and $\mathrm{L}$

Anterior; middle; posterior

Throbbing; constant; sharp; like a pressure; other $\mathrm{Y} / \mathrm{N}$

$\mathrm{Y} / \mathrm{N}$

$<60$ s; $1-5$ min; 5-60 min; 60 min-12 h, 12-24 h? $24-48 \mathrm{~h} ?>48 \mathrm{~h}$

$\mathrm{Y} / \mathrm{N}$

Always; never; sometimes

$\mathrm{Y} / \mathrm{N}$

$\mathrm{Y} / \mathrm{N}$ found a strong association between peri-ictal headache and seizure focus lateralization in patients with TLE (27 of $30=90 \%$ ), but not in patients with ETE ( 2 of $17=12 \% ; p$ $<0.0001$ ). This was true both for preictal headache (TLE: 9 of 10; ETE: 0 of 1) and postictal headache (TLE: 24 of 27 $=89 \%$; ETE: 2 of $17=12 \% ; p<0.0001$ ).

Peri-ictal headache conformed to the diagnostic criteria for migraine without aura (common migraine) of the IHS $^{5}$ in 18 of $30(60 \%)$ patients with TLE and in 7 of $17(41 \%)$ of those with ETE ( $p=0.24)$. The others had insufficient clinical features for migrainous headache as defined by the IHS.

Interictal headache. Interictal recurrent headaches or migraine were found in 31 of $100(31 \%)$ patients and were reported by 20 of $60(33 \%)$ patients with TLE and 11 of 40 $(27 \%)$ with ETE $(p=0.66)$. Twenty-nine patients (29 of $100=29 \%$ ) had a positive family history of recurrent headaches or migraine. Two patients reported migraine with aura. One patient with TLE who had no peri-ictal headache reported scintillating scotomatas preceding migrainous headaches. Another patient with right TLE reported episodes of scintillating scotomatas with

Table 2 Peri-ictal headache in 100 patients with partial epilepsy

\begin{tabular}{|c|c|c|c|}
\hline $\begin{array}{l}\text { Peri-ictal } \\
\text { headache }\end{array}$ & $\begin{array}{l}\text { Temporal } \\
\text { lobe } \\
\text { epilepsy }\end{array}$ & $\begin{array}{c}\text { Extratemporal } \\
\text { lobe } \\
\text { epilepsy }\end{array}$ & $p$ Value* \\
\hline Occurrence & $30 / 60(50)$ & $17 / 40(43)$ & NS \\
\hline $\begin{array}{l}\text { Ipsilateral to the } \\
\text { epileptic focus }\end{array}$ & $27 / 30(90)$ & 2/17 (12) & $<0.0001$ \\
\hline $\begin{array}{l}\text { With migrainous } \\
\text { character }\end{array}$ & $18 / 30(60)$ & $7 / 17(41)$ & NS \\
\hline
\end{tabular}

Value in parentheses are percentages.

$* p<0.05$ was considered to be significant (Fisher's exact test). paresthesias of the left hand followed by frontal headache. She also had preictal prodromal headache characterized by throbbing pain in the right temple with nausea and photophobia lasting many hours and never preceded by visual symptoms. The others had insufficient clinical features for migrainous headache as defined by the IHS. No patient described symptoms compatible with cluster headaches or other craniofacial algias.

Discussion. In our population of 100 consecutive patients with pharmacologically refractory partial epilepsy, we found a strong association between the side of peri-ictal headache and seizure focus lateralization in patients with TLE, but not in patients with partial epilepsy of extratemporal lobe origin. Of the three TLE patients with peri-ictal headache that was not colocalized with the seizure focus, two had bilateral headache, and only one had contralateral pain. Thus, we believe that peri-ictal headache, used in conjunction with other electroclinical and radiologic data, should be considered as a reliable and valuable clinical symptom in the lateralization of the epileptic focus in patients with TLE. However, evidence available about headache laterality is not sufficient to resolve discrepancies between other types of lateralizing information or strong enough that invasive monitoring might not be required.

The pathophysiology of peri-ictal headache is unclear. However, the migrainous character of the periictal headache in approximately half of our patients and $60 \%$ of those with TLE suggests a similarity between the pathophysiologic mechanism of periictal pain and that of primary headache syndromes, namely, a neurovascular origin. Studying the exposed human cerebral cortex during epileptic seizures, Penfield and Jasper ${ }^{6}$ observed widespread 
vasodilation and reactive prolonged postictal hyperemia in large pial veins over the discharging epileptic focus. Therefore, local vasodilatation of painproducing large cranial vessels and dura mater, and consequent stimulation of the trigeminal sensory nervous pain pathways, seems to be a key mechanism underlying the generation of headache associated with epileptic seizures. Individual susceptibility for activation of this system could explain why only approximately half of patients with partial epilepsy have peri-ictal headache.

The reason that patients with TLE have mainly unilateral pain as opposed to those with ETE is probably multifactorial. Different sites of seizure origin and, consequently, different patterns of dural stimulation could provide a plausible explanation for this clinical observation. Feindel et al. ${ }^{7}$ observed that manipulation of the sinuses adjacent to the tentorium during temporal lobectomy produced pain, which is felt behind the eye on the same side of the stimulation. In contrast, unilateral dural stimulation over the hemispheres can elicit bilateral or contralateral pain, probably because of the bilateral termination of the dural nerves near the midline. ${ }^{8-10}$ These observations could explain, at least in part, why patients with seizures originating in mesial temporal structures more frequently experience unilateral headache.

The difference between the pattern of referred pain in patients with TLE and those with ETE also could be explained by the tendency of epileptic activity in seizures originating outside the temporal lobe to be more diffuse and therefore lead to more widespread involvement of pial vessels. Furthermore, well-localized unilateral ictal pain generally occurs contralateral to an epileptic focus in the postcentral gyrus or neighboring parietal lobe. ${ }^{2}$

\section{References}

1. Schon F, Blau JN. Post-epileptic headache and migraine. J Neurol Neurosurg Psychiatry 1987;50:1148-1152.

2. Young GB, Blume WT. Painful epileptic seizures. Brain 1983; 106:537-554.

3. Isler H, Wieser HG, Egli M. Hemicrania epileptica: synchronous ipsilateral ictal headache with migraine features. In: Andermann F, Lugaresi E, eds. Migraine and epilepsy. Boston, MA: Butterworth, 1987;249-263.

4. Laplante P, Saint-Hilaire JM, Bouvier G. Headache as an epileptic manifestation. Neurology 1983;33:1493-1495.

5. Headache Classification Committee of the International Headache Society. Classification and diagnostic criteria for headache disorders, cranial neuralgias and facial pain. Cephalalgia 1988;8:1-96.

6. Penfield W, Jasper HH. Epilepsy and the functional anatomy of the human brain. Boston: Little Brown, \& Co, 1954.

7. Feindel W, Penfield W, McNaughton FL. The tentorial nerves and localization of intracranial pain in man. Neurology 1960; 10:555-563.

8. Wirth FP, Van Buren JM. Referral of pain from dural stimulation in man. J Neurosurg 1971;34:630-642.

9. Lesser RP, Luders H, Klem G, Dinner DS, Morris HH 3d, Hahn J. Ipsilateral trigeminal sensory responses to cortical stimulation by subdural electrodes. Neurology 1985;35:1760 1763.

10. Ray BS, Wolff HG. Experimental studies on headache: painsensitive structures of the head and their significance in headache. Arch Surg 1940;41:813-856. 


\section{Neurology}

Lateralizing value of peri-ictal headache: A study of 100 patients with partial epilepsy

A. Bernasconi, F. Andermann, N. Bernasconi, et al.

Neurology 2001;56;130-132

DOI 10.1212/WNL.56.1.130

This information is current as of January 9, 2000

Updated Information \& Services

References

Permissions \& Licensing

Reprints including high resolution figures, can be found at: http://n.neurology.org/content/56/1/130.full

This article cites 8 articles, 4 of which you can access for free at: http://n.neurology.org/content/56/1/130.full\#ref-list-1

Information about reproducing this article in parts (figures,tables) or in its entirety can be found online at:

http://www.neurology.org/about/about_the_journal\#permissions

Information about ordering reprints can be found online: http://n.neurology.org/subscribers/advertise

Neurology ${ }^{\circledR}$ is the official journal of the American Academy of Neurology. Published continuously since 1951, it is now a weekly with 48 issues per year. Copyright. All rights reserved. Print ISSN: 0028-3878. Online ISSN: 1526-632X.

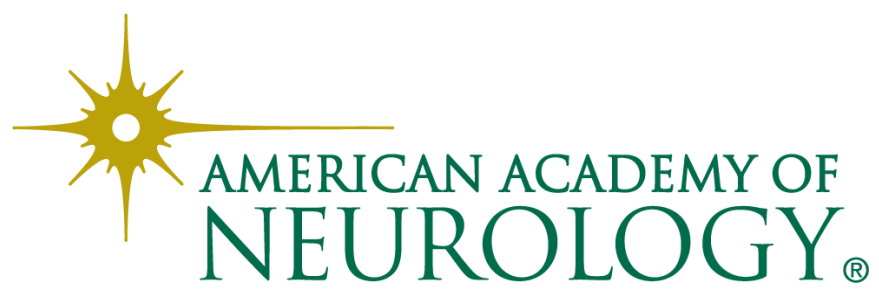

